\title{
Severe Plastic Deformation by Equal Channel Angular Pressing: Product Quality and Operational Details
}

\author{
Anibal de Andrade Mendes Filho*, Erika Fernanda Prados, Gustavo Trindade Valio,
}

\author{
José Benaque Rubert, Vitor Luiz Sordi, Maurizio Ferrante
}

\author{
Departamento de Engenharia de Materiais, Universidade Federal de São Carlos - UFSCar, \\ CEP 13565-905, São Carlos, SP, Brazil
}

Received: February 21, 2011; Revised: June 20, 2011

\begin{abstract}
As a technique, Equal Channel Angular Pressing (ECAP) is simple and inexpensive. However, if die manufacture and operational details are not carefully planned and implemented, difficulties arise, which can interfere with the product characteristics and the pressing operation itself. The present paper offers guidelines on die design and manufacture, emphasizing geometry, material and heat treatment. Further, operational parameters such as lubrication, pressing temperature, deformation routes, die closure procedure and the influence of channel cross section on maximum acceptable load are described. Additionally, the effects of those variables on the product characteristics (deformation level and homogeneity) and integrity, plus process control and safety, are discussed.
\end{abstract}

Keywords: ECAP, die geometry, die manufacture, ECAP operation

\section{Introduction}

During the last decade of the $\mathrm{XX}^{\text {th }}$ century the expression Severe Plastic Deformation (SPD) came into use to designate a technology able to promote profound changes on the microstructure and properties of metals and alloys. The most important effect of any SPD process is an accentuated grain size reduction that leads to substantial strength increase.

Metals and alloys subjected to SPD processing are known as ultrafine - grained materials, and are customarily classified as ${ }^{1}$ :

- Nanometric - those having grains size in the range 10-100 nm;

- Sub-micrometric or ultra-fine-grain size below $1000 \mathrm{~nm}$.

The present work will only deal with the latter type of processes, of which three representative examples are given in Chart 1. Among those, the process denominated Equal Channel Angular Pressing (ECAP) possesses the largest application potential due to the feasibility of scaling the product up to commercial dimensions ${ }^{2}$.

During ECAP - deformation, the sample transverse section is unchanged, thus permitting an infinite number of pressings or passes, $\mathrm{N}$ (in practice $\mathrm{N}$ is between four and eight). Another advantage is the sheer simplicity of the equipment, composed only of one press and a die, plus load recording and deformation speed control instrumentation.

The great majority of articles dealing with SPD are on microstructural evolution and grain size reduction mechanisms $\mathrm{s}^{3-5}$, mechanical properties ${ }^{6,7}$, functional properties, such as superplasticity and hydrogen storage $\mathrm{e}^{8-10}$, deformation and annealing textures ${ }^{11,12}$, and ductilization mechanisms ${ }^{13-16}$. This last topic is being intensively studied, since the high strength produced by the hyperdeformation reduces the work hardening rate and consequently leads to low ductility ${ }^{17}$.

SPD processing is the object of a number of biannual dedicated conferences, and two recent review papers show that it is an active, mature, and quite promising technology as far as future applications are concerned ${ }^{18,19}$. The aim of the present work is to describe ECAP as a technology, mainly in terms of die design and construction, die and press preparation, practical operational details and problems arising during pressing. These topics are seldom seen in the technical literature, although they certainly are of utmost interest for researchers interested on ECAP technology.

\section{Equal Channel Angular Pressing as a Technology}

\subsection{Die design}

Figure 1 shows the channel geometry and highlights its two most important parameters:

- $\Phi$ angle: defined at the channels' ${ }^{\prime}$ intersection; in most cases its value is set at $120^{\circ}$ or $90^{\circ}$ and is a parameter exerting a very strong influence on the deformation level;

- $\Psi$ angle: as shown in Figure 1, it derives from the curvature radii: $\mathrm{R}$ (external) and $\mathrm{r}$ (internal radius).

The sample is manually inserted in the entrance channel, pressed, and deformed by simple shear while is moved through the intersection. The equivalent strain $\varepsilon$ is calculated making use of the Iwahashi formula ${ }^{20}$, see insert in Figure 1, where $\mathrm{N}$ is the number of passes and $\gamma$ the shear strain. There is no consensus regarding the exit channel dimensions. Some designers prefer to reduce its cross section so as to exert some counter pressure on the sample. Others prefer to enlarge that section so as to reduce wall friction and consequently the pressing load.

The von Mises strains per pass for dies designed with angles $\Phi$ equal to $120^{\circ}$ and $90^{\circ}$ are $\approx 0.7$ and $\approx 1.0$, respectively. Only small changes of $\varepsilon$ with $\Psi$ are observed when the angle differs from zero, that is, when $\mathrm{R}$ and $\mathrm{r}$ are different from zero ${ }^{21}$. However, that same angle $\psi$ affect the deformation homogeneity and the pressing force. In a recent study this dependence was determined employing both physical and Finite Elements (FEM) simulations on $\mathrm{Pb}-\mathrm{Sn}$ and $\mathrm{Al}-\mathrm{Cu}$ samples. The samples were billets having a $7 \times 14 \mathrm{~mm}^{2}$ cross section and $70 \mathrm{~mm}$ length, on which a $1 \times 1 \mathrm{~mm}$ square grid was inscribed on one of their sides. This billet was adjoined to another with identical dimensions and pressed trough a $14 \times 14 \mathrm{~mm}^{2}$ channel, in a die fitted 
with interchangeable plates, so as to give different $\mathrm{R}$ and $\mathrm{r}$ values. In such a way, by changing said parameters it was possible to optimize $\Psi$ with respect to deformation homogeneity and pressing force. Figure 2 gives two examples of the above described physical and FEM simulations, performed on $\mathrm{Al}-4 \% \mathrm{Cu}$ samples. Shear deformation was measured directly on the real sample, and from the FEM simulation it was possible to calculate the deformation homogeneity (in \%) by equating it to the ratio of the homogenous deformation $\left(\mathrm{A}_{\mathrm{h}}\right)$ area over the total area $\left(\mathrm{A}_{\mathrm{t}}\right)$. Results of the studies above described are seen in Figure 3, showing the correlation of $\gamma, \mathrm{R}$ and $\mathrm{r}$, and in Figure 4, which depicts how pressing force varies with both $\mathrm{R}$ and $\mathrm{r}$. Finally, Table 1 summarizes FEM data regarding deformation homogeneity. All data regard samples obtained after one pass in a $120^{\circ}$ die.

Chart 1. Description of three important SPD processes, capable of producing sub-micron grain size.

\begin{tabular}{|c|l|}
\hline \multirow{1}{*}{$\begin{array}{c}\text { Severe } \\
\text { plastic } \\
\text { deformation } \\
\text { (SPD) }\end{array}$} & $\begin{array}{l}\text { ECAP: takes place in a die containing two channels } \\
\text { which meet at an angle } \Phi \text {. The material, a billet with } \\
\text { either square or circular section, is repeatedly forced } \\
\text { through the channels and is heavily deformed by } \\
\text { simple shear. Typically, the process produces grains } \\
\text { between } 600 \text { and } 300 \mathrm{~nm} .\end{array}$ \\
\cline { 2 - 3 } & $\begin{array}{l}\text { High Pressure Torsion }(H P T) \text { : a small disk is } \\
\text { subject to compression and torsion forces by a } \\
\text { shear and nanosized grains can be thus obtained. }\end{array}$ \\
\cline { 2 - 3 } & $\begin{array}{l}\text { Accumulated rolling: a plate is rolled using a } \\
\text { conventional rolling mill. After deformation the } \\
\text { sample is cut in half and the two halves thus obtained } \\
\text { are rolled together. Reduction per pass is normally } \\
\text { close to 50\%, corresponding to an equivalent strain } \\
\text { of 0.8; this procedure is repeated many times and the } \\
\text { resulting grain size is in the submicrometer range. }\end{array}$ \\
\hline
\end{tabular}

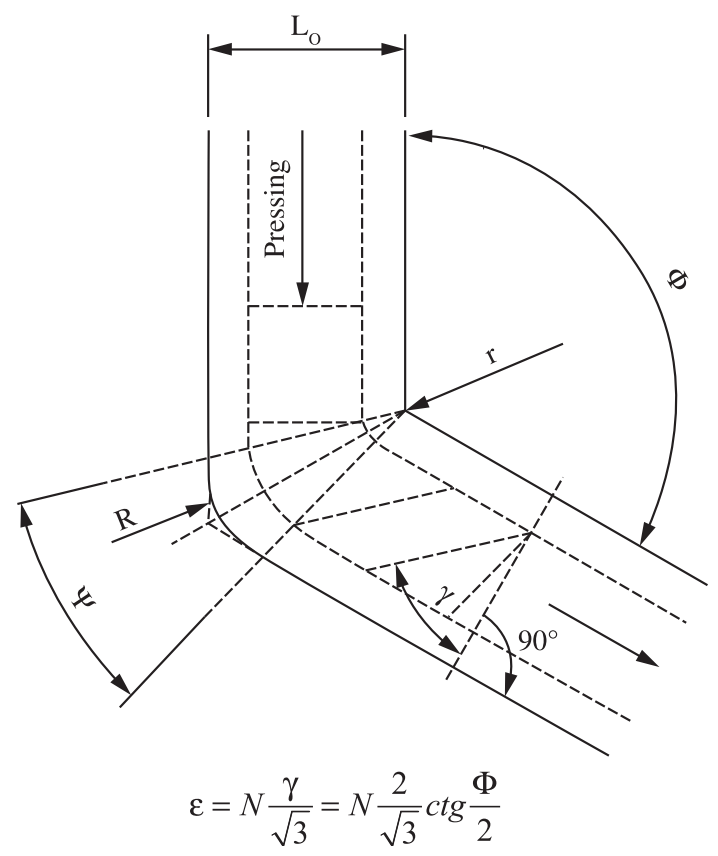

Figure 1. Geometrical features of the ECA channels, plus the formula employed for the calculation of the von Mises deformation when $\Psi=0$.
From the experiments just described it can be concluded that the larger $\Psi$, the lower is the pressing force. Although this is a practical advantage, both deformation level and deformation homogeneity decrease; therefore, a compromise must be found. This investigation showed that, in the present processing conditions, the best relationship between pressing force and deformation homogeneity, was observed when the combination of radii gave $\Psi=32^{\circ}$, that is:

- $\mathrm{r}=0 \mathrm{~mm}$ (sharp corner); $\mathrm{R}=8 \mathrm{~mm}$.

\subsection{Route for die manufacture}

In the construction of ECAP dies, high quality steels should be selected and one of the best choices is the AISI H13, a Cr-V-Mo alloy steel, probably the most popular hot-work tool steel. Recalling that ECAP - deformation of $\mathrm{Al}$ and other low strength alloys is better performed $25^{\circ} \mathrm{C}$, this choice gives more versatility to the die, since that steel is also suitable for room temperature work. Usually the channels are machined by spark erosion followed by manual polishing using emery paper \#320 to 1200 , a procedure that gives a surface roughness close to $0.05 \mu \mathrm{m}$. Conventional machining with special tools is also possible. The die is then heated to $1100-1200{ }^{\circ} \mathrm{C}$, oil quenched and subjected to double temper. The steel tempering curve must be known in order to avoid reaching maximum hardness, since cracks can develop during use when square section channels are employed. Thus, the tempering temperature must be higher than that giving maximum hardness, aiming to the reduction of residual stresses and to $50 \mathrm{Rc}$ or slightly less. Finally, after heat treatment the channels are nitrited or carbonitrited; besides giving a surface hardness of 60-65 Rc, this treatment reduces billet/channel wall friction which in its turn reduces pressing force. A final manual polishing with \# 400-600-1200 emery paper is necessary to remove surface imperfections resulting from the surface treatment. Figure 5 shows a schematic of the ECAP process and the photograph of an open die with $\Phi=120^{\circ}$.

\subsection{ECAP operational variables}

These variables are four: lubrication, pressing temperature, pressing parameters and deformation routes or modes. Additionally, because of its practical importance some remarks on the die closing technique may come useful:

- Lubrication: synthetic grease based on $\mathrm{MoS}_{2}$ is universally adopted. Plenty of it must be used and careful cleaning of the channel after each pass is recommended, particularly when deformation is carried out at high temperature. Fumes can develop when the process is carried out above $250{ }^{\circ} \mathrm{C}$, therefore good room ventilation and operator protection are essential;

- Temperature: the lowest possible to avoid dynamic recovery. For ductile materials such as $\mathrm{Al}$ and $\mathrm{Cu}$ alloys there is no reason to operate above room temperature, except when processing high strength $\mathrm{Al}$ alloys such as the 7000 series. However, steels, $\mathrm{Ti}$ and $\mathrm{Ti}$ alloys are normally pressed at moderate temperature, although it has been shown that commercially pure Ti can be ECAP-deformed at room temperature ${ }^{22,23}$;

- Deformation routes: after the first pass the billet can be rotated around its longitudinal axis and then placed back in the channel. Such rotation can assume different modes, giving origin to different deformation paths or routes. There are four basic deformation routes in ECAP; each of these introduces different slip systems thus defining the final microstructure ${ }^{24}$; and

- Die closing technique: this is an important detail since burrs can easily be formed on the sample while pressing in an incorrectly closed die. This occurrence causes a drastic increase of pressing force, often leading to process interruption when not to die fracture. Figure 6 is a photograph of an instance 

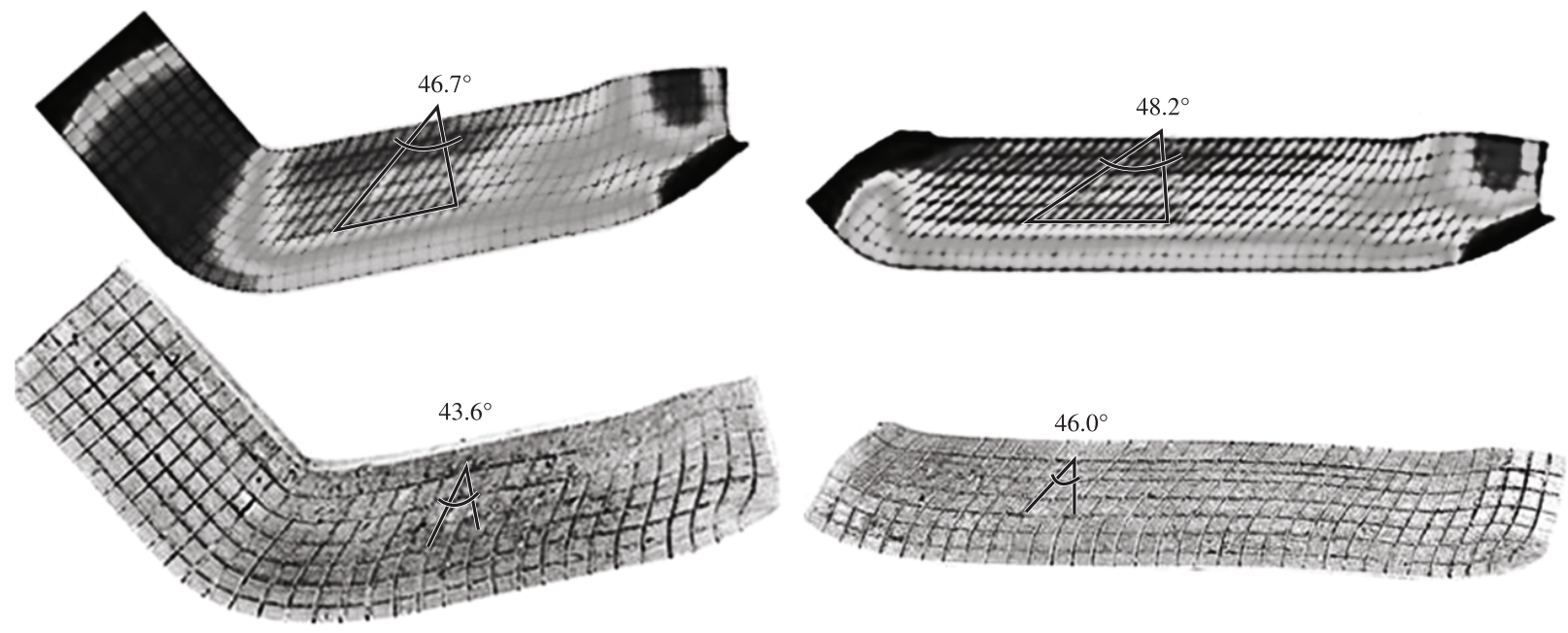

Figure 2. Examples of FEM simulation (above) and physical simulation (below) of ECAP - deformation. The material is an $\mathrm{Al}-4 \% \mathrm{Cu}$ alloy, and the die parameters are $\Phi=120^{\circ}, \mathrm{R}=14 \mathrm{~mm}, \mathrm{r}=0\left(\psi=60^{\circ}\right)$. Billets were subjected to an incomplete (left) and to a complete pass (right).

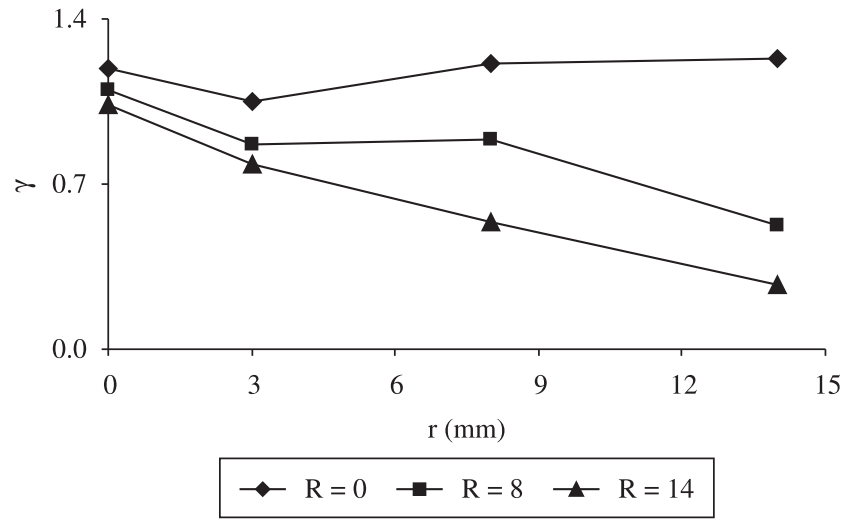

Figure 3. Dependence of ECAP shear strain $\gamma$ with $r$, for three different values of R; one pass in a $120^{\circ}$ die $^{7}$.

of burr formation. The problem can be avoided by carefully controlled die closing techniques. This means that bolts need to be correctly selected and carefully tightened, certifying that a suitable and even torque has been applied to each screw.

Torque must be selected according to the bolt class; for instance, for a $12 \mathrm{~mm}$ diameter class 12.9 (high strength class) socket head bolt, having a minimum tensile stress of $1220 \mathrm{MPa}$ and a yield stress equal to $90 \%$ of $\sigma_{\mathrm{y}}$, the recommended torque at room temperature is equal to 147.1 N.m. (IS0 4762 / DIN 912).

As for the tightening sequence and method, it differs whether it regards room or medium-high temperature operation. In the former case screws are initially tightened up to $80 \%$ of the specified torque. Those located in the central part of the die should be tightened first, and final tightening must be carried out under an external load (provided by the press) of, say, 5 t. For medium-high temperature service, screws must be re-tightened once the die temperature has been reached. This temperature must be considered when selecting the maximum torque, and the room temperature procedure is then repeated. Of course, in all cases a torquemeter must be used:

- Channel cross section: when dealing with high strength materials a first thought is that by reducing the channel section, pressing forces will also be reduced. This is true but it must be realized that punch section is also reduced, thus
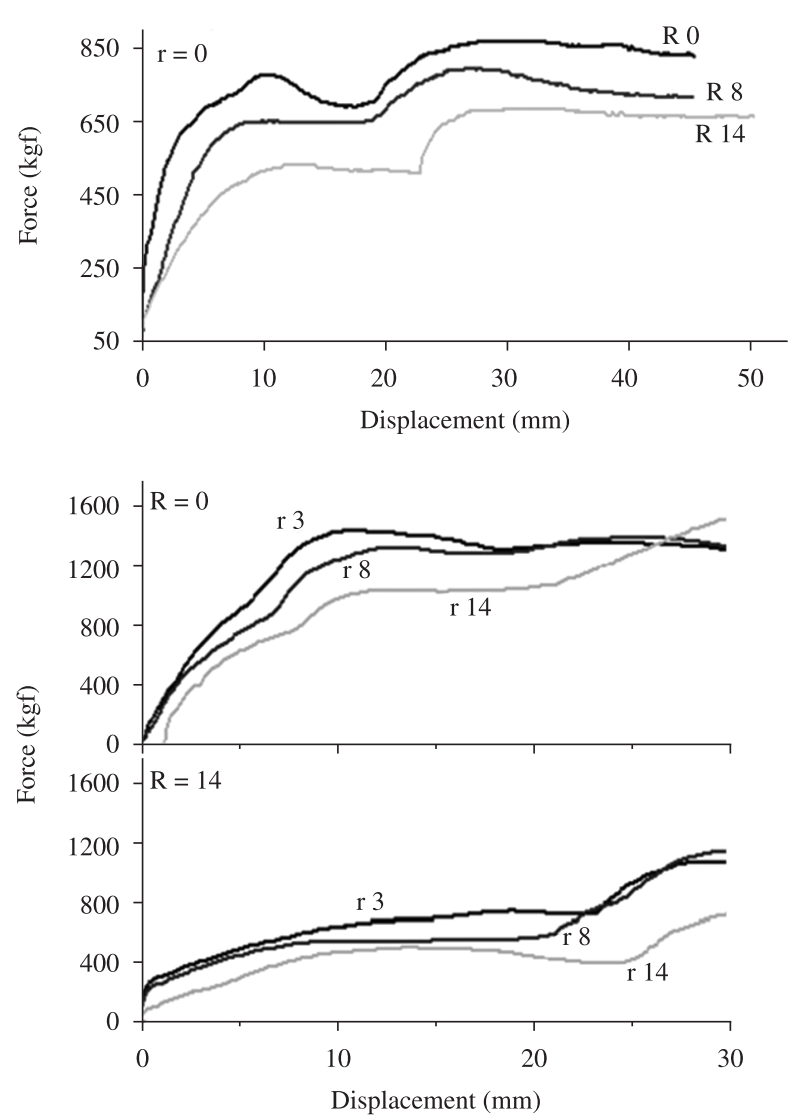

Figure 4. First pass ECAP pressing force agains plunger displacement for different combinations of $\mathrm{R}$ and $\mathrm{r}^{7}$. Data taken on $\mathrm{Pb}-62 \%$ samples.

Table 1. Relationship between $\psi$ and deformation homogeneity ${ }^{6}$.

\begin{tabular}{lccc}
\hline \multicolumn{1}{c}{ Sample } & $\mathrm{R} / \mathrm{r}(\mathrm{mm} / \mathrm{mm})$ & $\Psi\left(^{\circ}\right)$ & $\mathrm{A}_{\mathrm{h}} / \mathrm{A}_{\mathrm{t}}(\%)$ \\
\hline $\mathrm{Pb}-\mathrm{Sn}$ & $0 / 0$ & 0 & 56 \\
& $8 / 0$ & 32 & 50 \\
& $14 / 0$ & 60 & 45 \\
\hline $\mathrm{Al}-4 \mathrm{Cu}$ & $8 / 0$ & 32 & 71 \\
& $14 / 0$ & 60 & 44 \\
\hline
\end{tabular}




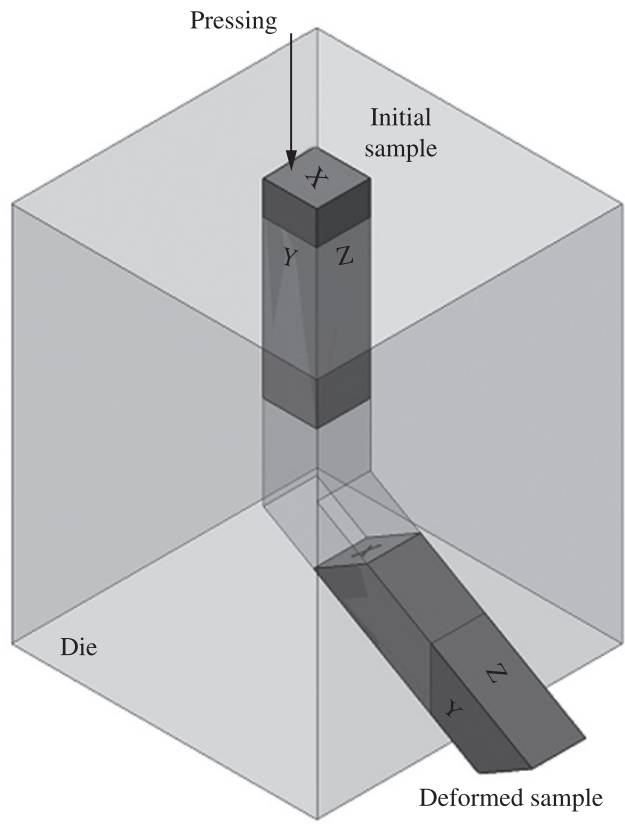

(a)

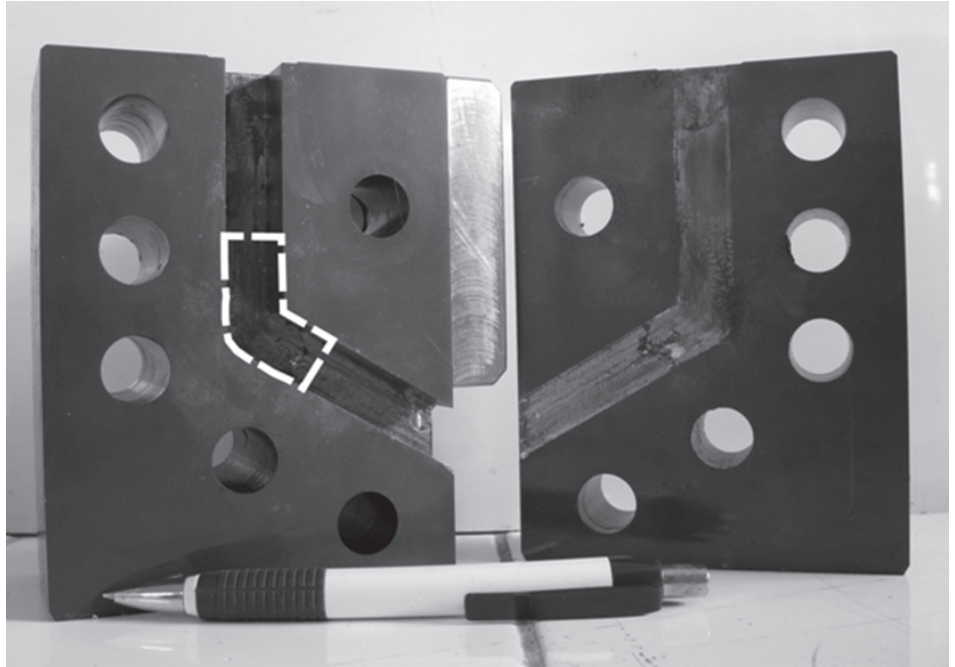

(b)

Figure 5. ECAP dies: a) schematic of a $\Phi=120^{\circ}$ die of closed construction, showing the sample with the planes orientation identification commonly used: $\mathrm{X}, \mathrm{Y}, \mathrm{Z}$; b) photograph of the two halves of a $\Phi=120^{\circ}$ die; the dotted profile represents a sample undergoing deformation.

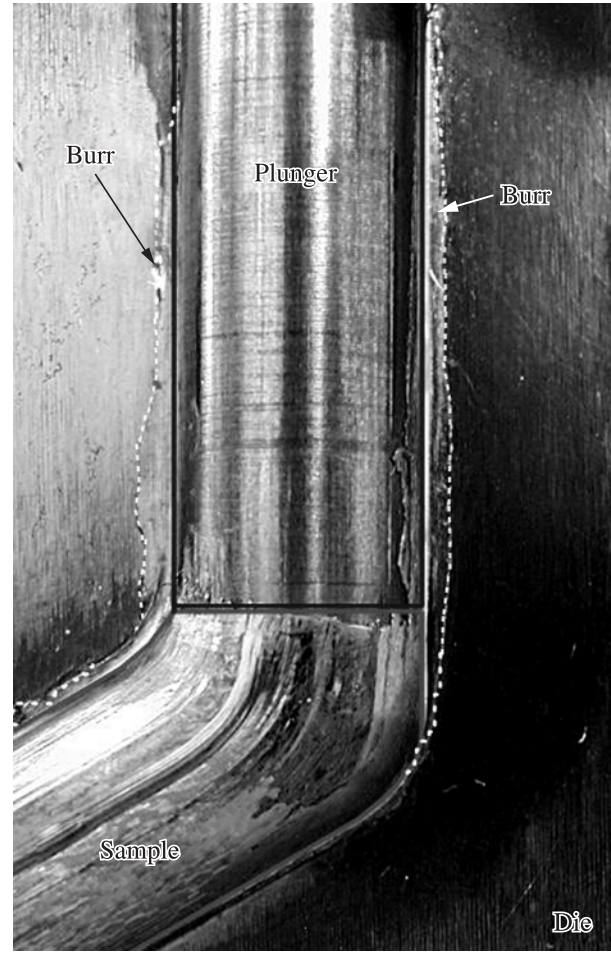

Figure 6. Burr formation during pressing of a Ti sample in a $120^{\circ}$ die, with a $10 \mathrm{~mm}$ diameter cylindrical channel ${ }^{7}$.

introducing buckling as a limiting factor. Figure 7 shows graphs of critical buckling load against the die punch aspect ratio (length/cross section area). The FEM program here employed deals with large plastic strains problems; it uses the central difference explicit method for time integration and an eight node hexahedral three dimensional solid elements with full

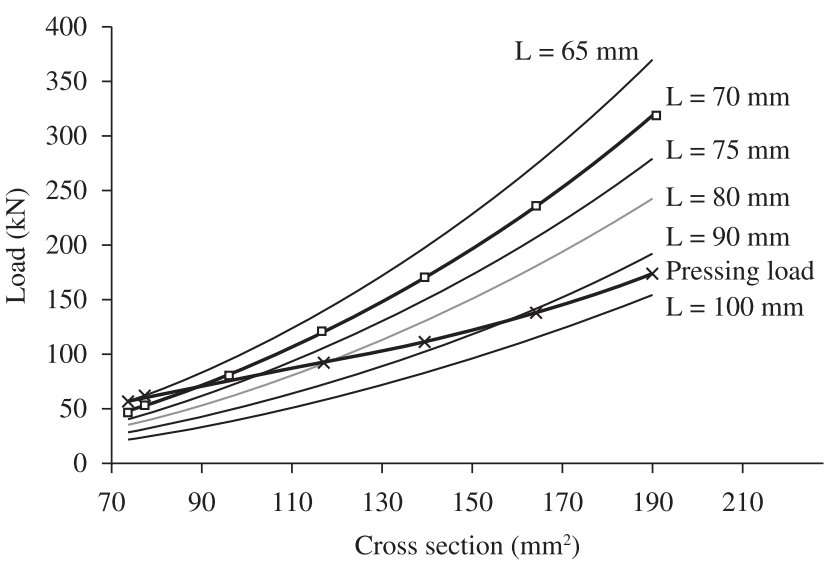

Figure 7. Relationship between buckling critical load and punch cross section and length. The curve relating the actual pressing load with the punch aspect ratio is included. The experimental data refers to a Grade 2 Ti billet with $75 \mathrm{~mm}^{2}$ cross section.

integration scheme and constant pressure to avoid volumetric locking. The elastoplastic analysis uses a hiperelastic model and the von Mises yield criteria with non-linear hardening. This produces a curve representing the actual force necessary to extrude a Grade 2 Ti billet (adopting friction coefficient equal to 0.05 ), which is included in the graph. Results show that in order to keep pressing forces below the critical value when the channel cross section is reduced, the punch length must also be decreased. For instance, considering a cross section of $100 \mathrm{~mm}^{2}$, the maximum punch length is $70 \mathrm{~mm}$. Above this value, the critical load will fall below the force necessary to press the sample, and once overload sets in, the punch suffers lateral deflection that invariably leads to its seizure or even its fracture. Summarizing, punches with aspect ratio locating them above the pressing load curve are safe. It must be recalled 


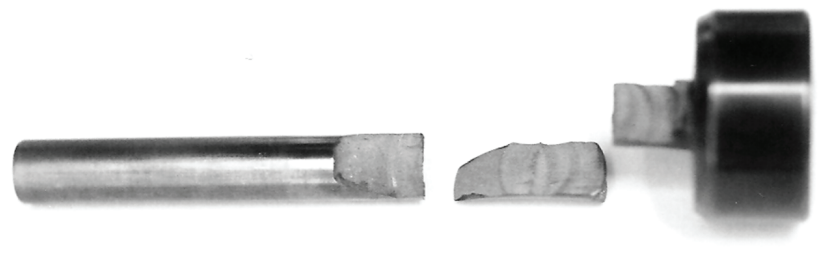

Figure 8. ECAP die punch fractured due to overload.

that for each material a different set of experimental data will results, thus a new pressing load curve will be generated and new relationships with punch aspect ratio will arise; and

- Safety considerations: usually, ECAP deformation is a slow process with pressing speeds in the range $10-50 \mathrm{~mm} / \mathrm{s}$. However, punch fracture can lead to the formation of debris which due to the high pressures involved can be projected with sufficient force to cause bodily harm. An instance of such occurrence is shown in Figure 8: a $10 \mathrm{~mm}$ diameter $70 \mathrm{~mm}$ length punch, fractured while pressing Ti grade 2 at room temperature, and debris flew across the room to a distance of approximately $10 \mathrm{~m}$. In order to prevent accidents of this sort it is recommended to surround the die with, for instance, a simple tube acting as a protection guard.

\section{Conclusion}

Due to the fact that ECAP is a relatively simple process, researchers tend not to be explicit on the experimental procedure they adopt. However, practice shows that there are numerous details from which product integrity, good process control and operator safety depend on. Among those, die design and heat treatment, plus correct die closure technique and good lubrication are of fundamental importance for smooth processing. Additionally, considerations regarding the relationship between punch stress distribution and buckling loads are necessary to guarantee a safe operation.

\section{References}

1. Gleiter H. Nanocrystalline materials. Progress in Materials Science. 1989; 33:223-315. http://dx.doi.org/10.1016/0079-6425(89)90001-7

2. Srinivasan S, Cherukury B and Chaudhury PK. Scaling up of equal channel angular pressing (ECAP) for the production of forging stock. Material Science Forum. 2006; 505-504:371-378.

3. Xu C, Furukawa M, Horita $\mathrm{Z}$ and Langdon TG. The evolution of homogeneity and grain refinement during equal-channel-angular pressing: a model for grain refinement. Material Science and Engineering A. 2005; 398:66-76. http://dx.doi.org/10.1016/j.msea.2005.03.083

4. Prangnell PB, Bowen JR and Gholinia A. The formation of submicron and nanocrystalline grain structure by severe deformation. In Proceedings of the 22th Ris $\phi$ International Symposium on Materials Science; 2001; Roskilde. Roskilde, Denmark: Ris $\varnothing$ National Laboratory; 2001. p. $105-126$

5. Bay B, Hansen N, Hughes DA and Kuhlmann-Wilsdorf D. Evolution of F.C.C. deformation structures in polyslip. Acta Metallurgica Materialia. 1992; 40:205-219. http://dx.doi.org/10.1016/0956-7151(92)90296-Q

6. Estrin Y. Effects of severe plastic deformation: mechanical properties and beyond. Materials Science Forum. 2006; 503-504:91-98. http://dx.doi. org/10.4028/www.scientific.net/MSF.503-504.91

7. Mendes Filho AA. Incremento de resistência mecânica em Titânio comercialmente puro por extrusão em canal angular - aplicação em implantes ortopédicos. [Dissertação]. São Carlos: Universidade Federal de São Carlos; 2010.
8. Kawasaki M, Mendes Filho AA, Sordi VL, Ferrante M and Langdon TG. Achieving superplastic properties in a $\mathrm{Pb}-\mathrm{Sn}$ eutectic alloy processed by equal-channel angular pressing. Journal of Materials Science. 2011; 46:155-160. http://dx.doi.org/10.1007/s10853-010-4889-2

9. Figueiredo RB and Langdon TG. Principles of grain refinement and superplastic flow in magnesium alloys processed by ECAP. Materials Science and Engineering A. 2009; 50:105-114. http://dx.doi. org/10.1016/j.msea.2008.09.058

10. Lima GS, Leiva DR, Huot J, Ishikawa T, Bolfarini C, Kiminami CS et al. Hydrogen activation behavior of commercial magnesium processed by different severe plastic deformation routes. Materials Science Forum. 2011; 667-669:1047-1052.

11. Jining Q, Han JH, Guoding $\mathrm{Z}$ and Lee JC. Characteristic of textures evolution induced by equal channel angular pressing in 6061 aluminium sheets. Scripta Materialia. 2004; 51:185-189. http://dx.doi.org/10.1016/j. scriptamat.2004.01.037

12. Kliauga AM, Ferrante M and Bolmaro RE. The evolution of texture in an AA 1050 alloy deformed by equal channel angular pressing. Materials Science Forum. 2011; 667-669:577-582. http://dx.doi.org/10.4028/www. scientific.net/MSF.667-669.577

13. Muñoz-Morris MA and Morris DG. Severe plastic deformation processing of $\mathrm{Al}-\mathrm{Cu}-\mathrm{Li}$ alloy for enhancing strength while maintaining ductility Scripta Materialia. 2010; 63 (3):304-307. http://dx.doi.org/10.1016/j. scriptamat.2010.04.022

14. Krasilnikov N, Lojkowski W, Pakiela $\mathrm{Z}$ and Valiev R. Tensile strength and ductility of ultra-fine-grained nickel processed by severe plastic deformation. Materials Science and Engineering A. 2005; 397:330-337. http://dx.doi.org/10.1016/j.msea.2005.03.001

15. Wang YM and Ma E. Strain hardening, strain rate sensitivity and ductility of nanostructures metals. Materials Science and Engineering A. 2004; 375-377:46-52. http://dx.doi.org/10.1016/j.msea.2003.10.214

16. Sabirov I, Estrin Y, Barnett MR, Timokhina I and Hodgson PD. Enhanced tensile ductility of an ultra-fine-grained aluminum alloy. Scripta Materialia. 2008; 58:163-166.

17. Ferrante M. A Short summary of present knowledge and some experimental observations on the ductility of sub-microcrystalline aluminium alloys. Materials Science Forum. 2010; 633-634:179-196. http://dx.doi.org/10.4028/www.scientific.net/MSF.633-634.179

18. Valiev RZ and Langdon TG. Principles of equal channel angular pressing as a processing tool for grain refinement. Progress in Materials Science. 2006; 51 (7):881-981. http://dx.doi.org/10.1016/j.pmatsci.2006.02.003

19. Meyers MA, Mishra A and Benson DJ. Mechanical properties of nanocrystalline materials. Progress in Materials Science. 2006; 51 (4):427-556. http://dx.doi.org/10.1016/j.pmatsci.2005.08.003

20. Iwahashi Y, Wang J, Horita Z, Nemoto M and Langdon TG. Principle of equal-channel angular pressing for the processing of ultra-fine grained materials. Scripta Materialia. 1996; 35:143-146. http://dx.doi. org/10.1016/1359-6462(96)00107-8

21. Furuno K, Akamatsu H, Oh-ishi K, Furukawa M, Horita Z and Langdon TG. Microstructure development in equal channel angular pressing using a $60^{\circ}$ die. Acta Materialia. 2004; 52:2497-2507. http://dx.doi.org/10.1016/j. actamat.2004.01.040

22. Mendes Filho AA, Sordi VL, Kliauga AM and Ferrante M. The effect of equal channel angular pressing on the tensile properties and microstructure of two medical implant materials: ASTM F-138 austenitic steel and Grade 2 titanium. Journal of Physics. Conference Series. 2010; 240:012130.

23. Zhao X, Yang X, Liu X, Wang X and Langdon TG. The processing of Ti through multipass of ECAP at room temperature. Materials Science and Engineering A. 2010; 527:6335-6339. http://dx.doi.org/10.1016/j. msea.2010.06.049

24. Nakashima K, Horita Z, Nemosto M and Langdon TG. Development of a multi-pass facility for equal channel angular pressing to high total strains Material Science and Engineering. 2000; 281:82-87. http://dx.doi. org/10.1016/S0921-5093(99)00744-3 